\title{
O CONTROLE DE CONSTITUCIONALIDADE PELOS TRIBUNAIS DE CONTAS: ANÁLISE DAS RECENTES DECISÕES DO TRIBUNAL DE JUSTIÇA DO ESTADO DO RIO GRANDE DO SUL
}

\author{
CONTROL OF CONSTITUTIONALITY BY AUDITORS COURTS: ANALYSIS OF \\ RECENT DECISIONS OF THE RIO GRANDE DO SUL STATE COURT
}

\section{Luís Antonio Zanotta Calçada}

\begin{abstract}
Doutorando em Direito no Programa de Pós-Graduação, Mestrado e Doutorado da Universidade de Santa Cruz do Sul. Mestre em Direito pelo Programa de Mestrado em Direito da Faculdade de Direito da Fundação Escola Superior do Ministério Público - FMP. Pós-graduado em Direito Administrativo. Pós-graduado em Gestão Pública. Auditor-fiscal da Receita Estadual. E-mail: lzanotta@terra.com.br.
\end{abstract}

\section{Janriê Rodrigues Reck}

Graduação em Ciências Jurídicas e Sociais pela Universidade do Vale do Rio dos Sinos. Mestrado pela Universidade de Santa Cruz do Sul. Doutorado em Direito pela Universidade do Vale do Rio dos Sinos. Professor do Programa de Pós-Graduação, Mestrado e Doutorado da Universidade de Santa Cruz do Sul.

Procurador Federal.

E-mail: janriereck@unisc.br.

Recebido em: 05/09/2019

Aprovado em: 27/04/2020

RESUMO: Este estudo versa sobre a possibilidade de controle de constitucionalidade pelos Tribunais de Contas. A partir da análise de recentes decisões prolatadas pelo Tribunal de Justiça do Estado do Rio Grande do Sul - TJ/RS, buscou-se verificar se aqueles julgados encontram sintonia com a doutrina e a jurisprudência do Supremo Tribunal Federal a respeito do tema. Apresentadas as funções dos Tribunais de Contas, perpassa-se pelas recentes decisões do TJ/RS sobre o exercício do controle de constitucionalidade pelas Cortes de Contas. Após, foram expostas críticas doutrinárias e jurisprudências a respeito da posição do TJ/RS. A análise foi realizada a partir de revisão bibliográfica e documental, utilizando o método indutivo. Ao final, concluiu-se que a posição do Tribunal de Justiça gaúcho, que defende a impossibilidade da análise da conformidade de leis locais frente à Constituição, é equivocada e apequena as importantes competências atribuídas ao órgão de controle pelo constituinte de 1988.

Palavras-chave: Controle de Constitucionalidade; Tribunal de Contas; Tribunal de Justiça do Estado do Rio Grande do Sul; Constituição Federal; Jurisprudência.

ABSTRACT: This study cross with the possibility of judicial review by the Audit Courts. From the analysis of recent decisions prolated by the State of Rio Grande do Sul -Court TJ/RS, we look for to verify whether those judged are in coherence with the doctrine and jurisprudence of the Federal Supreme Court on the topic. Having presented the functions of the Courts of Auditors, we run through the recent decisions of the TJ/RS on the exercise of judicial review by the Courts of Accounts. After, doctrinal comment and jurisprudence about the position of the TJ / RS were exposed. The analysis was performed from bibliographic and documentary revision, using the inductive method. In the end, it was concluded that the position of the Court 
of State, which argument the impossibility of analyzing the review of local laws with the Constitution, is mistaken and diminishes the important competences attributed to the control body by the framers of 1988 Constitution.

Keywords: Constitutionality Control; Audit Office; Court of Justice of the State of Rio Grande do Sul; Federal Constitution; Jurisprudence.

SUMÁRIO: Introdução. 1 Os tribunais de contas e o controle de constitucionalidade. 2 A posição atual do tribunal de justiça do estado do rio grande do sul. $3 \mathrm{O}$ controle de constitucionalidade pelos tribunais de contas e crítica à posição do tribunal de justiça do estado do rio grande do sul; Conclusão; Referências.

\section{INTRODUÇÃO}

Os Tribunais de Contas são primordiais na defesa do interesse público. Não obstante, são poucos os que os conhecem e, dentre esses, há ainda aqueles que não compreendem propriamente a extensão das competências desses órgãos de controle.

De fato, a sociedade, de modo geral, apreende bem as funções desempenhadas pelos tradicionais Poderes Executivo, Legislativo e Judiciário. Para além da questão histórica, são essas as instituições responsáveis pela execução das atividades-fim do Estado, ou seja, aquelas em relação às quais a população mantém contato direto. Como se verá adiante, todavia, para que tais prestações de serviços públicos sejam realizadas em conformidade com o ordenamento jurídico e de forma efetiva, eficaz e eficiente, é imprescindível o trabalho "silencioso" das Cortes de Contas.

Nessa linha, é importante destacar a função dos Tribunais de Contas no contexto do ordenamento jurídico brasileiro e suas competências, dentre as quais a possibilidade de realizar o controle incidental de constitucionalidade. Ocorre que tal competência poderia colidir com o centrismo do Poder Judiciário na determinação do que é contrário à Constituição da República Federativa do Brasil, sendo necessário verificar, no âmbito do Estado do Rio Grande do Sul, qual o entendimento atual do Tribunal de Justiça a respeito do tema. Refletindo-se sobre a exegese contemporânea da Corte gaúcha, torna-se essencial explorar o entendimento da doutrina e do Supremo Tribunal Federal (STF), procedendo-se a uma análise crítica a respeito das decisões prolatadas.

Assim, o presente estudo presta-se a verificar se as recentes decisões prolatadas pelo Tribunal de Justiça do Estado do Rio Grande do Sul - TJ/RS encontram sintonia com a doutrina e a jurisprudência do Supremo Tribunal Federal a respeito da possibilidade de controle de constitucionalidade pelas Cortes de Contas.

Considerada a temática proposta, o método a ser empregado será o indutivo. A partir da criação dos Tribunais de Contas e da fixação de suas atribuições constitucionais, serão apresentados dois acórdãos atuais proferidos pelos órgãos colegiados do Tribunal de Justiça do Estado do Rio Grande do Sul sobre a possibilidade de controle de constitucionalidade, realizando, posteriormente, o exame das decisões. A pesquisa terá uma abordagem qualitativa, com investigação bibliográfica e documental.

\section{OS TRIBUNAIS DE CONTAS E O CONTROLE DE CONSTITUCIONALIDADE}

A criação de Tribunais de Contas no território brasileiro ocorreu com a instituição do que seria hoje o Tribunal de Contas da União, por intermédio do Decreto $\mathrm{n}^{\circ}$ 966-A, de 7 de novembro de 1890 (BRASIL, 1890). Na exposição de motivos realizada por Rui Barbosa (1946), pode-se verificar a importância de tal órgão.

De acordo com o autor, a Corte de Contas é a coroação das providências necessárias que a sociedade pode exigir de seus representantes. Em que pese constar na exposição de motivos a "necessidade de tornar o orçamento uma instituição inviolável e soberana" (1946, p. 
361), não se deve circunscrever a frase somente às peças orçamentárias. O orçamento é somente uma personificação do que será realizado pela Administração. Então, acima de tudo, deve-se entender a referência ao orçamento como a própria Gestão Pública. O ideal é a existência de um órgão que garanta uma Administração Pública inviolável e soberana. Além de uma preocupação econômica de não haver déficits, que se pode entender como má administração, Rui Barbosa vai além, coadunando-se em uma visão hobbesiana de que "que toda reunião, por mais livre que seja [...] de modo que as partes reunidas se empenham em conseguir algum benefício, ou aquele mesmo eudokimeirt que alguns estimam e honram junto àqueles com quem conviveram" (HOBBES, 2002, p. 27), ao tentar blindar, com tal órgão, o Estado de "atentados contra a lei, inspirados em aspirações opostas ao interesse geral" (BARBOSA, 1946, p. 362), perpetrados por governantes.

Assim, o Tribunal de Contas seria uma proteção democrática contra desmandos e tentativas de obtenção de vantagens em desfavor da sociedade. Esse pensamento é corroborado pela opção realizada por Rui Barbosa ante as suas possibilidades de configuração da Corte - a Francesa e a Italiana - optando pela segunda pelos seguintes motivos (1946, p. 369):

Não basta julgar a administração, denunciar o excesso cometido, colher a exorbitância, ou a prevaricação, para as punir. [...] Convém levantar, entre o poder que autoriza periodicamente a despesa e o poder que quotidianamente a executa, um mediador independente, auxiliar de um e de outro, que, comunicando com a legislatura, e intervindo na administração, seja, não só o vigia, como a mão forte da primeira sobre a segunda, obstando a perpetração das infrações orçamentarias por um veto oportuno aos atos do executivo, que direta ou indireta, próxima ou remotamente discrepem da linha rigorosa das leis de finanças.

Para tal desiderato, a fim de que não houvesse influências dos gestores nas decisões do Tribunal, foi necessário que esse "tivesse posição autônoma, com atribuições de revisão e julgamento, cercado de garantias contra quaisquer ameaças", para que possa "exercer as suas funções vitais no organismo constitucional, sem risco de converter-se em instituição de ornato aparatoso e inútil" (BARBOSA, 1946, p. 363). Para tanto, os Tribunais de Contas são dotados de independência, com autonomia para o exercício de suas atribuições, a fim de garantir a imparcialidade.

Não se pode negar o fato de Tribunais de Contas defenderem direitos fundamentais da sociedade, pois o direito à boa Administração Pública é um direito fundamental, se tratando de "[...] um direito de natureza fundamental do cidadão, segundo o qual se pode facilitar o exercício dos direitos fundamentais sociais [...]" (RODRÍGUEZ-ARANA MUÑOZ, 2015, p. 598).

As atribuições dos Tribunais de Contas de zelar pela regularidade dos atos da Administração Pública perfeitamente se encaixam na sistemática de checks and balances. Se o objetivo do sistema é de, com a "tripartição dos Poderes", um deles fiscalizar possíveis excessos por parte dos outros, evitando ilegalidades e abusos, apesar de não ser considerado como tal, os Tribunais de Contas certamente se encaixariam nessa sistemática. Essa função é estampada na carta de demissão de Serzedello Correa do cargo de ministro da Fazenda em 1893, motivada por estudos da Presidência da República visando à alteração das funções do Tribunal, a qual foi publicada pelo Jornal do Commercio de 30 de abril de 1893 (O SR. EX-MINISTRO DA FAZENDA, 1983, p. 2):

Esses decretos annullão o Tribunal, reduzem-no á simples chancela do Ministro da Fazenda, tirão-lhe toda a independencia e autonomia, deturpão os fins da instituição e permittiráõ ao Governo a pratica de todos os abusos e, vós o saberis - é preciso antes de tudo legislar para o futuro

$[\ldots]$ 
Os governos nobilitão-se, Marechal, obedecendo a essa soberania suprema da lei, e só dentro della elles sentem-se fortes e são verdadeiramente independentes.

Qual é, porém, o inconveniente em ouvir-se previamente o Tribunal?

Há, então, a figura da independência dos Tribunais de Contas, sob pena de, em não ocorrendo, serem apenas um carimbador dos atos dos demais Poderes, chancelando-os e conferindo a esses um manto de legalidade. Após a criação, em todas as Constituições brasileiras, houve a previsão da existência de um Tribunal de Contas, mantendo-se inalterada a essência desse. ${ }^{1}$

Na Constituição Federal de 1988 (BRASIL, [2016]), o artigo 70 determina que a fiscalização contábil, financeira, orçamentária, operacional e patrimonial da União e das entidades da administração direta e indireta, é realizada, como controle externo, pelo Congresso Nacional, com o auxílio do Tribunal de Contas da União, inserindo as competências específicas desses no artigo 71. Apesar de constar como órgão auxiliar, não há qualquer tipo de subordinação entre o Congresso Nacional e o Tribunal de Contas da União (e pelo princípio da simetria, entre as Assembleias Legislativas e os Tribunais de Contas Estaduais). Os Tribunais de Contas, assim como os demais Poderes, possuem autonomia administrativo-financeira, formulando seu orçamento com competência para propositura de Projetos de Leis acerca da remuneração de servidores e estrutura funcional, dentre outras possibilidades de exercício de competências próprias. Isso possibilita que tais cortes atuem equidistantes dos interesses dos demais órgãos de Estado, para que a execução de suas atividades seja realizada com independência e imparcialidade.

Para fins metodológicos, a disciplina do artigo 70 da Carta Magna será classificada em objeto da fiscalização e forma da fiscalização: como objeto temos a fiscalização (a) contábil (verificação dos registros contábeis de acordo com os princípios e normas que regem a matéria, tais como relevância, materialidade e representação fidedigna); (b) financeira (a atividade financeira do Estado não compreende somente a obtenção de receitas, mas também do gasto público); (c) orçamentária (compreendendo todo o planejamento e a execução dos gastos públicos constantes nas peças orçamentárias: o Plano Plurianual, a Lei de Diretrizes Orçamentárias e a Lei Orçamentária Anual); (d) operacional (busca avaliar o desempenho da gestão pública, por exemplo na avaliação de impacto ou de resultado de uma política pública); e (e) patrimonial (controle dos bens, direitos e valores públicos).

As formas de fiscalização são quanto à (a) legalidade (conformidade com o ordenamento jurídico, incluindo o constitucional e os princípios da Administração Pública); (b) legitimidade (se os atos buscam a justiça e o interesse da sociedade), (c) economicidade (não é a avaliação de economia financeira, mas, sim, a análise de eficiência, eficácia e efetividade); e (d) aplicação das subvenções e renúncia de receitas (se em algum dos atos houve qualquer tipo de investimento sem retorno - contraprestação, como nas subvenções sociais - ou renúncia de receita pública).

Como se pode verificar, desde os primórdios da criação dos Tribunais de Contas esses sempre atuaram de forma a preservar a probidade e o agir finalístico da Administração Pública. A extensão da atuação das Cortes, todavia, não é tema pacífico. Muito se questiona a possibilidade de ação dos Tribunais de Contas em determinadas questões, entre elas a possibilidade de controle de constitucionalidade, por intermédio de negativa de executoriedade de norma inconstitucional.

Sendo o Tribunal de Contas órgão administrativo, a discussão sobre a sua possibilidade de examinar a conformidade de leis e atos normativos frente à Constituição insere-se no contexto do debate travado sobre o poder dever de realizar controle de constitucionalidade atribuído a outras instituições de mesma natureza.

\footnotetext{
${ }^{1}$ Quadro comparativo entre as Constituições até a de 1967, é formulado por Mariana Montebello Willeman (2017. p. 145-146).
} 
No cenário brasileiro, antes da promulgação da Constituição de 1988 o entendimento era pela permissividade (MENDES, 1997, p. 12). Após, ocorreu certa limitação no campo do controle, pelo fato da Carta Magna ter aumentado o número de legitimados para a propositura de Ações Diretas de Inconstitucionalidade, ensejando discussões sobre a legitimidade de autoridades que não no rol da CF. Situação semelhante é encontrada na doutrina alienígena, em que se questiona quem deve interpretar a Constituição. Se a Carta não é dirigida exclusivamente aos órgãos judiciários - mas sim a todos os cidadãos e órgãos do Estado, incluindo os administrativos - indaga-se se o Poder Judiciário deveria ser o único interprete da Constituição (ALEXANDER; SCHAUER, 1997, p. 1359).

De fato, a interpretação das normas refoge às competências de um único órgão, uma vez que o Direito (e as normas) incide sobre toda a sociedade. Em outras palavras: se todos os cidadãos e o próprio Estado devem seguir a Constituição, a todos deve igualmente ser facultado interpretar os ditames lá insculpidos. Ao se ter um único intérprete da Constituição, corre-se o risco de a suprema autoridade exegética ser insuficientemente estimulada a motivar suas decisões (GANT, 1997, p. 373) - o que, no Brasil, se denomina Supremocracia. Nesse sentido, Edwin Meese III (1986-1987, p. 985-986) afirma que cada um dos três poderes constitucionais, independentes e harmônicos (“o Executivo e o Legislativo, não menos que o Judiciário") possui o dever de serem intérpretes constitucionais.

Glauco Salomão Leite (2017, p. 234), a partir de uma visão de um constitucionalismo dialógico entre os poderes, entende que a "interpretação constitucional não pode ficar enclausurada na Poder Judiciário, de sorte que os demais atores estatais e sociais apresentam credenciais que os legitimam a participar da concretização constitucional". Aqui, o autor referese às políticas públicas, verdadeiros instrumentos de efetivação da Carta, notadamente aqueles que exigem do Estado prestações positivas. Como o Poder Executivo poderia, por exemplo, saber o que está incluso no conceito de direito social à saúde - para executar políticas públicas voltadas à implementação desse direito - sem incorrer em interpretação constitucional. Assim, a própria consecução dos direitos fundamentais pressupõe a interpretação constitucional.

Outro exemplo é a divulgação do valor dos vencimentos de servidores públicos. Ao publicar os dados, o administrador deve ponderar entre a prevalência do direito fundamental à privacidade ou do princípio constitucional da transparência e do controle social. Ou seja: exigese da Administração o exercício da atividade interpretativa em relação a preceitos constitucionais.

Então, se há a interpretação constitucional por parte de todos os componentes do Estado (sejam pessoas ou órgãos), haverá sempre um controle de constitucionalidade das normas por eles, o que passa necessariamente pela chamada "negativa de executoriedade de leis inconstitucionais". Para Gustavo Binenbojm (2014, p. 275) esse instituto é um corolório da própria supremacia da Constituição e se inclui entre as competências dos Tribunais de Contas (2014, p. 277). Corroborando o entendimento, Ricardo Guastini (2009, p. 52-55) acrescenta que a interpretação das leis conforme a constituição é fruto da força vinculante da Constituição, sendo tal imposição um princípio hermenêutico a ser utilizado na aplicação de todo o ordenamento jurídico. Seguindo essa linha, ao negar o cumprimento de uma norma inconstitucional, os demais órgãos (Executivo e Legislativo) não atuam ao arrepio da lei, mas sim conforme a Constituição.

No âmbito do Direito Constitucional Lusitano, Jorge Miranda (2014, p. 227-229), afirma, a respeito do assunto, haver "o poder, e o dever", de não aplicar normas inconstitucionais, existindo em determinações situações a negativa de se executar normas inconstitucionais. In casu, o jurista entende que os responsáveis (no Direito Português) a negarem aplicação à norma inconstitucional são os tribunais administrativos (p. 230)

De fato, em uma sociedade plural e complexa, a interpretação constitucional limitada a somente um órgão acaba por restringir a supremacia das disposições constitucionais e se revelar anti-democrática, uma vez que a Carta vincula todos os envolvidos na Administração Pública: os democraticamente eleitos, ou não. Assim, a possibilidade de um órgão, com as atribuições e a importância dos Tribunais de Contas, exercer o controle de constitucionalidade deve ser considerada. 
Para fins deste artigo serão analisados dois acórdãos do Tribunal de Justiça do Estado do Rio Grande do Sul (TJ/RS), um do final do ano de 2018 e outro de abril de 2019, para se verificar qual é o entendimento atual do TJ/RS. Após, tais decisões serão examinadas sob o prisma da possibilidade do controle de constitucionalidade pelos Tribunais de Contas à luz da doutrina e da orientação contida nos julgados do Supremo Tribunal Federal, guardião da Constituição.

\section{A POSIÇÃO ATUAL DO TRIBUNAL DE JUSTIÇA DO ESTADO DO RIO GRANDE DO SUL}

Pode-se afirmar que houve um giro jurisprudencial no TJ/RS acerca da possibilidade de controle de constitucionalidade por parte dos Tribunais de Contas. Se outrora o Tribunal "demonstrava uma falta de clareza sobre a compreensão do conteúdo e extensão da Súmula n. 347, limitando-se a reproduzir seu texto e reafirmar a sua vigência, sem maiores enfrentamentos teóricos e práticos" (BITENCOURT; RECK, 2016, p. 194), nos dois julgados, objetos do estudo, vislumbra-se que o TJ/RS repele a vigência da Súmula ${ }^{\circ} 347$ do Supremo Tribunal Federal, apresentando argumentos para a não aplicação dessa. A referida súmula afirma que o "Tribunal de Contas, no exercício de suas atribuições, pode apreciar a constitucionalidade das leis e dos atos do Poder Público".

Feitas tais observações iniciais, passa-se à apresentação dos acórdãos. Em ambos os processos os relatores concederem liminar para afastar decisões do TCE/RS e, em seus votos, acabaram por transcrever, parcial ou totalmente, os argumentos expostos quando da concessão daquela. Com relação às partes, nas duas oportunidades o impetrante foi o Estado do Rio Grande do Sul.

Na primeira decisão houve o questionamento de ato do TCE/RS que suspendeu um concurso público para oficiais militares pela Corte de Contas, por considerar inconstitucional o limite de idade para ingresso nos quadros da Brigada Militar (nomenclatura da polícia militar no Rio Grande do Sul) para os civis e não para os militares. De acordo com o relatório, o TCE/RS entendeu haver infringência ao princípio da isonomia, por tratar de forma desigual (existência de limitação de idade) os iguais (candidatos), ordenando, em sede cautelar, a retificação do edital. Irresignado, o Estado do Rio Grande do Sul impetrou Mandado de Segurança, postulando, conforme o relatório do acórdão,

[...] a anulação da determinação do Tribunal de Contas do Estado contida no processo $n^{\circ} 000574-02 / 18-7$, confirmada nos EDs $n^{\circ} 968-02.00 / 18-9$, tendo em vista a inaplicabilidade dos precedentes desta Corte citados pelo Conselheiro em seu voto, a impossibilidade do exercício do controle de constitucionalidade pelo Tribunal de Contas, a inobservância da cláusula de reserva de plenário pela Segunda Câmara do TCE e a revisão do mérito da decisão da autoridade impetrada.

Por sua vez, a autoridade demandada afirmou que, além de existir afronta ao princípio da isonomia, não houve usurpação de competência do Poder Judiciário, "tendo em vista ter sido postergada a análise quanto à constitucionalidade da legislação citada pelo Relator do TCE"; portanto não teria ocorrido o "afastamento da aplicação da lei estadual, mas apenas a determinação de suspensão do certame a fim de que fossem promovidas alterações no edital". Além de tais pontos, defendeu a "existência de previsão constitucional de medida cautelar pelos Tribunais de Contas, decorrente da aplicação da teoria dos poderes implícitos", e a inexistência da alegada desconformidade à reserva de plenário. Considerado o objeto deste artigo, não se adentrará na discussão e argumentos acerca de eventual não atendimento à reserva de plenário, cingindo-se à aplicabilidade da Súmula nº 347 do STF.

Conforme já referido, foi concedida a suspensão do ato da autoridade administrativa em caráter liminar, dentre outros, pelos motivos a seguir, extraídos do voto do acórdão: 
[...] procede, a uma primeira vista, a argumentação do Impetrante de que a declaração de inconstitucionalidade, ainda que de forma incidental, não é tarefa reservada à Corte de Contas, observado o sistema de controle de constitucionalidade instituído pela Constituição Federal em vigor.

A tal respeito, pertinente a invocação ao que já assentado pela jurisprudência do Pretório Excelso, como, por exemplo, no MS n 25888 por seu eminente relator, Ministro Gilmar Mendes, sobre a impossibilidade jurídicoconstitucional, na atual quadra do Direito Constitucional Brasileiro, de que órgãos administrativos, inclusive os Tribunais de Contas, proclamem, em abstrato, a inconstitucionalidade de normas legais, situação que sequer se confunde com a simples não aplicação de leis inconstitucionais e que, hodiernamente, exige submissão da questão supostamente inconstitucional ao controle judicial competente, por parte de quem detém a devida legitimidade.

O TJ/RS, ao invés de reprisar a Súmula $\mathrm{n}^{\circ} 347$ sem qualquer tipo de análise crítica, como vinha fazendo até então, passou a emitir seu juízo de valor a respeito do tema. $\mathrm{O}$ que antes era aceito sem quaisquer tipos de questionamento, agora passou a ser afastado com base em uma decisão judicial da Suprema Corte. Acerca da possibilidade de controle de constitucionalidade pelo Tribunal de Contas, há somente tal argumento, sendo as demais motivações para a concessão da segurança a reserva de plenário e o próprio entendimento da norma sobre limite de idade. Não há qualquer tipo de fundamentação teórica a respeito da matéria além da referência ao $\mathrm{MS} \mathrm{n}^{\circ} 25888$, tanto que tal referência consta na ementa, da qual se retira o seguinte trecho:

[...] 1. A declaração de inconstitucionalidade, ainda que de forma incidental, não é tarefa reservada à Corte de Contas, observado o sistema de controle de constitucionalidade instituído pela Constituição Federal em vigor. Compreensão atualmente adotada pelo STF, conforme MS 25888/Rel. Min. Gilmar Mendes.

Com relação ao segundo julgado, foi impetrado Mandado de Segurança contra o conselheiro do TCE/RS que, conforme relatório, determinou ao Estado do Rio Grande do Sul, por intermédio de um dos secretários de Estado, que "se abstenha de praticar qualquer ato do qual possa resultar a demissão de pessoal e/ou a desmobilização das estruturas administrativa e operacional no âmbito das Fundações arroladas na Lei Estadual n ${ }^{\circ}$ 14.982/2017”. O Estado do Rio Grande do Sul, ato reflexo, ajuizou o writ alegando: “(a) usurpação de competência exclusiva do Poder Judiciário; (b) inobservância da cláusula de reserva de Plenário; (c) invasão de competência privativa do Governador do Estado". Nos pedidos formulados, solicitou a anulação do ato que determinou a suspensão dos procedimentos de desmobilização ou, subsidiariamente, que o processo em trâmite perante a Corte de Contas fosse inserido em pauta para julgamento pelo Tribunal Pleno do TCE/RS. Não há qualquer alegação, pela parte impetrante, sobre a impossibilidade de controle de constitucionalidade (incidental, no caso) do lado do Tribunal de Contas, muito menos a respeito da inaplicabilidade da Súmula ${ }^{\circ} 347$. Quando a autoridade coatora prestou as informações pertinentes, foi suscitada a matéria, posto que, dentre a inúmera fundamentação apresentada, fora afirmado que "não houve usurpação de competência do Poder Judiciário, uma vez que a decisão proferida limitou-se à fiscalização quanto ao fiel cumprimento da lei, além de ainda estar vigendo a súmula 347 do STF". Assim como destacado na outra decisão avaliada, não são fruto de análise, neste, os demais argumentos.

A liminar foi deferida e o processo remetido para julgamento. No voto, o relator frisou que o TCE/RS infringiu a competência privativa do Poder Judiciário para exercer o controle de constitucionalidade, passando a repisar os termos da medida liminar, destacando-se os seguintes excertos a respeito do tema aqui tratado: 
Nesse sentido, pode (e deve) o TCE fiscalizar o cumprimento da lei, o que é diverso de afastar a aplicação de dispositivo legal, que cumpriu o correspondente processo legislativo.

Isso porque, não está dentre as funções do TCE o afastamento de lei estadual por entendê-la contrária a princípios esculpidos na Constituição Federal.

$[\ldots]$

Não se desconhece o teor da súmula 347 do STF, que prevê "O Tribunal de Contas, no exercício de suas atribuições, pode apreciar a constitucionalidade das leis e dos atos do Poder Público." Todavia, referida súmula foi aprovada em 1963, antes, portanto, da Constituição de 1988.

Tal questão - possibilidade do Tribunal de Contas afastar aplicação de ato normativo por julgar inconstitucional - já foi submetida à Suprema Corte, no MS 25888.

[...]

Com efeito, o controle de constitucionalidade, a partir da Constituição Federal, é de competência exclusiva do Poder Judiciário.

Apresentadas as explicações relativas ao controle difuso e incidental, o relator concluiu, em sede liminar, afirmando que "tudo isso reforça a ausência de legitimação de Conselheiro do TCE para afastar a aplicação de lei por considerar incompatível com a Constituição Federal". Acostada a transcrição da medida liminar, o relator continua o voto destacando que o TCE/RS exorbitou de suas funções, pois o teor da decisão da Corte de Contas deveria abranger somente a fiscalização do ato e não o afastamento dos efeitos, uma vez que incorre em violação à competência privativa do Poder Judiciário. O desembargador Francisco José Moesch manifestou-se no sentido de não ser competência da "Corte de Contas exercer o controle difuso de constitucionalidade no julgamento de seus processos, diante do regramento constitucional vigente em nosso país", apresentando os argumentos da concessão de medida liminar nos autos do Mandado de Segurança $n^{\circ}$ 35.410/DF, concluindo pela impossibilidade de "Conselheiro do Tribunal de Contas do Estado afastar a aplicação de lei que entenda incompatível com a Constituição Federal, como na hipótese".

Houve, nesse caso, maior argumentação sobre as atribuições dos Tribunais de Contas e a competência para a declaração de inconstitucionalidade de leis. Nos fundamentos foram citadas posições doutrinárias, desenvolvendo-se o tema em conjunto com duas decisões do STF já utilizadas para a concessão da liminar e não meramente o represamento de decisões anteriores. É mister destacar que essa temática não foi a única motivação para o provimento do pedido da parte impetrando.

Cumpre salientar que a primeira decisão é mais hodierna que a segunda, mas pelo fato de conter uma fundamentação mais extensa do que aquela, optou-se por discorrer em ordem cronológica decrescente.

Demonstra-se, a partir das duas decisões colacionadas, que o TJ/RS indica ter alterado o entendimento sobre a possibilidade de o Tribunal de Contas exercer o controle de constitucionalidade, negando executoriedade a normas infraconstitucionais em detrimento do comando externado na Súmula $\mathrm{n}^{\circ} 347$ do STF. Ainda, diferentemente da argumentação utilizada quando do sentido contrário (mera citação à súmula), no segundo julgado trouxe posições doutrinárias sobre o tópico.

O referido verbete, todavia, ainda subsiste no ordenamento jurídico. Também existem posições doutrinárias que concluem pelo controle de constitucionalidade, em caráter difuso, pelos Tribunais de Contas, motivo pelo qual se realizará o estudo de tais itens e a análise crítica das decisões apresentadas.

3 O CONTROLE DE CONSTITUCIONALIDADE PELOS TRIBUNAIS DE CONTAS E CRÍTICA À POSIÇÃO DO TRIBUNAL DE JUSTIÇA DO ESTADO DO RIO GRANDE DO SUL 
O controle de constitucionalidade, na maneira insculpida pela legislação pátria, pode ocorrer de forma principal-abstrata/concentrada ou incidental/difusa (MENDES, 2015, p. 1047). A abstrata é somente arguida perante o Supremo Tribunal Federal. A incidental seria exercida pelos demais órgãos do Poder Judiciário (a opção pela expressão "seria" é proposital).

Nessa, não há uma ação questionando a inconstitucionalidade de uma norma, mas, sim, a de um ato jurídico, fundamentado em norma supostamente contrária à Carta, ou seja, o exame da inconstitucionalidade da lei é matéria prejudicial para o deslinde do feito. A análise é realizada no caso concreto: a norma não desaparece do sistema jurídico, não sendo, então, invalidada; o que se fasta é apenas a aplicação da norma inconstitucional no caso em exame, "podendo ainda ter aplicação noutro feito, a menos que o poder competente a revogue" (BONAVIDES, 2004, p. 303). Assim, a norma considerada inconstitucional somente é afastada para o deslinde do processo, equivalendo a uma negativa de executoriedade dessa, por contrariedade constitucional.

Isso posto, deve-se avaliar sobre os partícipes do controle de constitucionalidade. Sobre a análise de constitucionalidade pelo Poder Judiciário não há maiores comentários a fazer, uma vez que se trata de disposição legal. Da mesma forma, é tranquila a possibilidade de controle realizada no âmbito das comissões de constituição e justiça no seio do processo legislativo. Quanto ao Poder Executivo, entende-se que este está autorizado a deixar de aplicar ato normativo manifestamente inconstitucional. Verifica-se, assim, a possibilidade de controle de constitucionalidade pelo Executivo, com a respectiva negativa de execução. Incumbe advertir que tal aspecto não é uniforme na doutrina, mas, para fins deste trabalho, serão apresentadas as posições que possibilitam o controle por outros órgãos.

Eventual negativa de cumprimento de norma constitucional ocorre justamente pelo princípio da supremacia da constituição. O cumprimento dos ditames constitucionais não é somente reservado aos Tribunais, mas a todos os indivíduos e órgãos, tanto privados quanto públicos. No caso dos órgãos públicos, as autoridades devem zelar "pela correta aplicação da Constituição, respeitando e fazendo respeitar sua supremacia" (DIMOULIS; LUNARDI, 2016, p. 26). Dessa forma, não é somente ao Poder Judiciário que caberia a análise de suposta inconstitucionalidade de norma, mas, sim, a todos os Poderes, que, além de cumprir, devem impedir o descumprimento (BINENBOJM, 2014, p. 262). Com base em tais argumentos, não há exclusividade para um órgão ou Poder exercer o controle de constitucionalidade. Negar a execução de atos com fundamento em normas inconstitucionais não é faculdade, mas dever de toda a Administração Pública. O que se torna privativo do Poder Judiciário é a possibilidade de exclusão da norma inconstitucional do ordenamento jurídico. Nas palavras de Ana Cláudia Nascimento Gomes (2002, p. 255), "portanto, em face da CF, não se deve considerar o princípio da reserva do juiz como sendo algo absoluto".

Negar a possibilidade de controle das normas pelo Executivo é um "apego ideológico à tese da inferioridade institucional do Executivo em relação aos demais poderes que teriam a capacidade, respectivamente, de legislar e de afastar leis inconstitucionais" (DIMOULIS; LUNARDI, 2016, p. 397). A respeito de mero cumpridor das normas, a "autoridade administrativa não pode ser vista como reles ou medíocre executora dos comandos legais, como subordinada auxiliar do legislador" (GOMES, 2002, p. 112). Se todas as funções de Estado estão em pé de igualdade e devem ser harmônicas entre si, não cabe ao Executivo tão somente ser um executor das construções legislativas e das decisões judiciais dentro do sistema de proteção à supremacia constitucional (não estamos mencionando o poder de veto pela capacidade de esse ser derrubado pelo Legislativo).

Aos Tribunais de Contas, como parte da Administração Pública, mas apartados do Poder Judiciário ou Legislativo, cabem as mesmas conclusões tecidas em relação ao Executivo. Tais Cortes, considerado o controle realizado conforme a competência estabelecida na Carta Magna, "têm o poder-dever de apreciar concretamente a constitucionalidade de leis e atos normativos subjacentes a atos e ajustes submetidos à sua apreciação" (WILLEMAN, 2017, p. 277-278). Em verdade, o controle de constitucionalidade não se trata de uma faculdade dos Tribunais de Contas, mas, sim, um dever. A fiscalização quanto à legalidade, determinada no artigo 71 da Constituição de 1988, não deve ser lida de forma literal, mas apenas com respeito 
à legislação infraconstitucional, e deve ser compreendida em um sentido amplo - de fiscalização quanto à regularidade do ato avaliado -, tendo como parâmetro o ordenamento jurídico como um todo. Considerando que, na visão kelseniana, a Constituição está no topo do sistema de normas, é corolário a obrigação de análise de constitucionalidade dos atos, afastando a incidência de dispositivos inconstitucionais quando com ela colidentes.

Nas palavras do conselheiro aposentado do TCE/RS, Hélio Saul Mileski, na obra $O$ controle da gestão pública (2011, p. 292), tem-se:

Logicamente que apreciar a constitucionalidade não significa poderes para decretar a inconstitucionalidade das leis e dos atos do poder público. Contudo, corno qualquer decisão decorrente de avaliação jurídica deve, necessariamente, repercutir num efeito prático, pois se assim não fosse, tratarse-ia de uma decisão inócua, pode-se afirmar que a apreciação de constitucionalidade realizada pelo Tribunal de Contas, embora não possa produzir a retirada do mundo jurídico das leis e atos analisados, opera o efeito de negar executoriedade aos textos examinados, obstando a continuidade de sua utilização, no sentido de evitar os decorrentes prejuízos de natureza jurídica, econômica e financeira.

Corroborando a ideia de que o controle de constitucionalidade pelos Tribunais de Contas não exclui a norma do ordenamento jurídico (controle concentrado), mas realiza um controle incidental, com a negativa de executoriedade, Ronaldo Chadid (2019, p. 180) afirma que não aplicar o ato infraconstitucional "não implica dizer que as Cortes de Contas fazem o controle de constitucionalidade nos moldes que ocorre na esfera judicial".

Negar que os Tribunais de Contas realizem controle de constitucionalidade quando do exercício das suas atividades finalísticas, negando executoriedade em caso de inconstitucionalidade do ato, é atrofiar todo o sistema de controle externo determinado constitucionalmente (WILLEMAN, 2017, p. 282). Impedir o Tribunal de Contas de exercer o controle de constitucionalidade é, por assim se dizer, inconstitucional, pois a fiscalização desses, quanto à legalidade/constitucionalidade dos atos da Administração Pública, consta na Carta Política Brasileira.

A questão em relação a essa possibilidade é que o controle pelo Executivo e/ou Tribunais de Contas em nada prejudica o sistema de controle de constitucionalidade pelo Poder Judiciário. A decisão do Poder Executivo ou dos Tribunais de Contas em negar aplicação de uma norma, por entender inconstitucional, poderá ser objeto de questionamentos no Poder Judiciário. O Judiciário, no âmbito do princípio da inafastabilidade da prestação jurisdicional, poderá anular ou referendar o ato. Toda a parte que se sentir prejudicada pelo afastamento da executoriedade de norma pelo Poder, poderá se socorrer no Poder Judiciário, que continuará com a "última palavra" sobre a constitucionalidade da norma.

Consequentemente, em nenhum momento haverá uma usurpação por parte dos Tribunais de Contas das atribuições concedidas ao Poder Judiciário de declarar a constitucionalidade da norma, posto que, ao afastar a incidência dessa, não estará invalidandoa em caráter geral.

Com relação aos aspectos jurisprudenciais, a Súmula $n^{\circ} 347$ do Supremo Tribunal Federal, citada nos julgados, e ainda hígida, foi formulada sob a égide da Constituição de 1946. Apesar de determinar que "O Tribunal de Contas, no exercício de suas atribuições, pode apreciar a constitucionalidade das leis e dos atos do Poder Público", o leading case não traz expressamente tal mérito. O caso que originou a súmula trata da negativa de executoriedade em um caso concreto, ao invés do exercício do controle concentrado de constitucionalidade (BRASIL, 1963):

Entendeu o julgado que o Tribunal de Contas não podia declarar a inconstitucionalidade da lei. $\mathrm{Na}$ realidade essa declaração escapa à competência específica dos Tribunais de Contas. 
Mas há de se distinguir entre declaração de inconstitucionalidade e não aplicação de leis inconstitucionais, pois esta é a obrigação de qualquer tribunal ou órgão de qualquer dos poderes do Estado.

Conforme o sumulado, o controle de constitucionalidade, exercido pelos Tribunais de Contas, pode ocorrer somente na forma incidental, afastando os efeitos de norma inconstitucional do caso concreto. Isso não difere de qualquer posição da doutrina, considerando-se caber a todos os componentes da federação a guarda da ordem constitucional.

Com relação à afirmativa da ementa do Mandado de Segurança 70079305702 supracitado, de que "a declaração de inconstitucionalidade, ainda que de forma incidental, não é tarefa reservada à Corte de Contas [...]. Compreensão atualmente adotada pelo STF, conforme MS 25888/Rel. Min Gilmar Mendes”, cabe a crítica de que a posição constante no MS n ${ }^{\circ} 25888$, de relatoria do ministro Gilmar Mendes, não é a posição da Corte constitucional brasileira. A decisão utilizada como fundamento foi exarada, monocraticamente, em sede liminar, e seu mérito ainda não foi julgado. Assim, não se pode afirmar ser essa a posição atualmente adotada pelo STF. Caso possamos utilizar tal inferência, a posição adotada pelo STF será sempre a decisão mais moderna, independentemente de ter sido prolatada monocraticamente por Turma ou pelo Tribunal Pleno. Cita-se, para averiguar o grau de insegurança jurídica que ocorreria se tratássemos qualquer tipo de decisão como a "compreensão atualmente adotada pelo STF" (para se utilizar dos termos da ementa), a discussão acerca da prisão de segunda instância, quando, apesar de precedente do Tribunal Pleno, há julgamentos que não o seguem.

Em referência ao controle incidental por órgãos alheios à atividade jurisdicional do Poder Judiciário, tanto a citada decisão não é a contemporânea que, em dezembro de 2016, o Tribunal Pleno do STF decidiu, por unanimidade (ausente o ministro Celso de Mello), o mérito à Petição $n^{\circ} 4.656$, indeferindo o pleito da parte autora, na qual o voto da relatora, ministra Carmen Lúcia, assentou a possibilidade dessa forma de controle de constitucionalidade por órgão externo ao Poder Judiciário, da qual se destaca, in verbis:

Nesses termos, concluída pelo Conselho Nacional de Justiça a apreciação da inconstitucionalidade de lei aproveitada como fundamento de ato submetido ao seu exame, poderá esse órgão constitucional de controle do Poder Judiciário valer-se da expedição de ato administrativo formal e expresso, de caráter normativo, para impor aos órgãos submetidos constitucionalmente à sua atuação fiscalizadora a invalidade de ato administrativo pela inaplicabilidade do texto legal no qual se baseia por contrariar a Constituição da República.

[...]

16. O exercício dessa competência implícita do Conselho Nacional de Justiça revela-se na análise de caso concreto por seu Plenário, ficando os efeitos da inconstitucionalidade incidentalmente constatada limitados à causa posta sob sua apreciação, salvo se houver expressa determinação para os órgãos constitucionalmente submetidos à sua esfera de influência afastarem a aplicação da lei reputada inconstitucional (Grifo nosso).

Antes de se adentrar no entendimento constante no voto, é imperioso salientar a posição do Conselho Nacional de Justiça - CNJ - na estrutura do Poder Judiciário. O CNJ é parte integrante do Poder Judiciário, entretanto não realiza a função judicante como os demais órgãos. Como bem-destaca Gilmar Ferreira Mendes, a "Emenda Constitucional n. 45/2004 criou o Conselho Nacional de Justiça com atribuição de efetivar a supervisão da atuação administrativa e financeira do Poder Judiciário" (2015, p. 1.021). Refoge das atividades atribuídas ao $\mathrm{CNJ}$ o julgamento de processos judiciais.

Cotejando-se as competências do Conselho com as dos Tribunais de Contas, verificase que as funções dos últimos são maiores do que as do primeiro. Se é possível ao "órgão de controle do Judiciário" realizar o domínio da constitucionalidade incidental, afastando a 
aplicação de norma nos casos concretos, não há qualquer motivo para que tal possibilidade também exista para o órgão de controle de toda a Administração Pública.

Tal entendimento da necessidade de se separar o controle incidental do concentrado, é bem-observado pela relatora Carmen Lúcia:

12. Quanto à natureza da decisão impugnada, há de se ter em conta a distinção entre a conclusão sobre o vício a macular lei ou ato normativo por inconstitucionalidade, adotada por órgão jurisdicional competente, e a restrição de sua aplicação levada a efeito por órgão estatal sem a consequência de excluí-lo do ordenamento jurídico com eficácia erga omnes e vinculante.

Após tal ponto, a ministra relatora trouxe magistério de Hely Lopes Meirelles, realizando, após colacionar o entendimento do autor, a seguinte nota:

Embora o enfoque desse entendimento dirija-se à atuação do Chefe do Poder Executivo, parecem ser suas premissas aplicáveis aos órgãos administrativos autônomos, constitucionalmente incumbidos da relevante tarefa de controlar a validade dos atos administrativos, sendo exemplo o Tribunal de Contas da União, o Conselho Nacional do Ministério Público e o Conselho Nacional de Justiça (grifo nosso).

A fundamentação para tal aplicabilidade aos órgãos de controle se deve ao fato de se tratar "de poder implicitamente atribuído aos órgãos autônomos de controle administrativo para fazer valer as competências a eles conferidas pela ordem constitucional". Se tal possibilidade é aplicável ao Tribunal de Contas da União, por simetria também cabe aos Tribunais de Contas dos Estados.

É importante citar que a ministra relatora, por diversas vezes, realizou digressão sobre a competência do controle incidental por esses órgãos de controle (no caso da decisão, o CNJ), isto é, buscou deixar claro que em nenhum momento estava havendo a exclusão da norma do ordenamento jurídico brasileiro, mas, sim, estava deixando de ser aplicada (uma negativa de executoriedade, como já mencionado), no caso em análise, pelo órgão, pois aquela declaração e invalidade erga omnes é de competência exclusiva dos órgãos de prestação jurisdicional do Poder Judiciário.

O voto do ministro Luiz Fux na Petição 4656 ressaltou justamente a natureza administrativa do CNJ, a ausência de função jurisdicional (como a dos Tribunais de Contas) e a viabilidade de controle de constitucionalidade:

Nesse ponto não se desconhece que, pela natureza eminentemente administrativa do Conselho Nacional de Justiça, o órgão não possui funções jurisdicionais, não atraindo competência, portanto, para realizar controle de constitucionalidade. Ocorre que o Conselho Nacional de Justiça pode afastar a aplicação de norma quando reconhecer sua inconstitucionalidade [...]

Após tal manifestação, para corroborar as afirmações, o ministro citou justamente o precedente da Súmula n 347, já supracolacionado.

Para se tecer uma melhor análise crítica das decisões do TJ/RS, lança-se fragmento do voto da relatora:

24. Concluo, entretanto, ter atuado o órgão de controle administrativo, financeiro e disciplinar da magistratura nacional nos limites de sua competência, afastando a validade dos atos administrativos e, para tanto, a aplicação de lei estadual como seu fundamento e que ele reputou contrária ao princípio constitucional de ingresso no serviço público por concurso público, pela ausência dos requisitos caracterizadores do cargo comissionado.

Não há declaração de inconstitucionalidade da qual resulte a anulação ou revogação da lei discutida, com exclusão de sua eficácia. Teve-se na espécie a nulidade dos atos questionados para o que se afirmou inaplicável, 
administrativamente, lei estadual com vício de inconstitucionalidade, vinculando-se apenas a atuação de órgão judicial cujos atos administrativos foram submetidos ao controle do Conselho Nacional de Justiça.

Não se há cogitar, portanto, de usurpação da competência deste Supremo Tribunal, a qual seria passível de impugnação por meio constitucional próprio, como efetivamente se deu.

Com relação aos casos julgados pelo TJ/RS, tem-se que o órgão de controle estadual não extirpou, em nenhum momento, as normativas estaduais do ordenamento jurídico. No primeiro caso, determinou a suspensão do concurso público e, no segundo, dos atos "do qual possa resultar a demissão de pessoal e/ou a desmobilização das estruturas administrativa e operacional no âmbito das Fundações arroladas na Lei Estadual $n^{\circ} 14.982 / 2017$ " (RIO GRANDE DO SUL, 2019). Fica cristalino, então, que não houve uma declaração de inconstitucionalidade, mas o mero afastamento de aplicação da norma, como bem-reconhecido pelo relator do segundo acórdão, Desembargador Luiz Felipe Silveira Difini, quando, em sede liminar, deferiu o pedido da parte autora, pois o dito ato coator não foi de tornar a norma inconstitucional, mas, sim, "afastar a aplicação de lei por considerar incompatível com a Constituição Federal" (RIO GRANDE DO SUL, 2019). O desembargador relator desse processo, ao cassar o ato de suspensão determinado pelo TCE/RS, o fez sem considerar a jurisprudência do STF a respeito da possibilidade de controle incidental de constitucionalidade, afastando a aplicação da norma inconstitucional no caso concreto.

Tal visão do Tribunal gaúcho pode ser entendida como não democrática. A democracia depende da participação de todos os integrantes da sociedade; não somente os indivíduos, mas também os órgãos. Muito se comenta sobre a posição do Judiciário como protetor da democracia para evitar uma ditadura da maioria. As Cortes de Contas, todavia, também fazem parte das instituições que buscam manter o caráter democrático e protetor dos princípios da Administração Pública. Como já frisado anteriormente, é possível aos Tribunais de Contas exercerem o controle de constitucionalidade, podendo seus atos serem analisados no caso de judicialização do tema. Se o TJ/RS exaurisse os fundamentos dos acórdãos apenas no mérito das questões, eventuais críticas se reduziriam à constitucionalidade da norma; porém, ao afirmar que não é cabível ao TCE/RS realizar o controle, tornaram as próprias decisões inconstitucionais.

A força centrípeta que o TJ/RS pretende dar ao controle de constitucionalidade incidental, de acordo com as decisões supra, remete à "necessidade de atualização da legislação para o aprimoramento democrático de algumas instituições, com o propósito de superar instâncias de autoritarismo incrustadas em órgãos típicos da democracia" (MOURÃO; SHERMAM; SERRA, 2018, p. 134). Tal posição pode ocasionar uma juristocracia constitucional. $^{2}$

\section{CONCLUSÃO}

O Tribunal de Contas detém uma função importante dentro da Administração Pública. São aqueles órgãos, com suas respectivas competências, que realizam o controle dos atos de gestão sem prescindir de qualquer tipo de impulso. Apesar de exercer função administrativa, devem fiscalizar todos os órgãos da Administração Pública sob diversos prismas, dentre os quais a legalidade. Considerada a supremacia constitucional, entretanto, a legalidade não deve se restringir apenas ao exame da lei em sentido estrito, mas, sim, ao complexo jurídico estatuído, principalmente a Carta Constitucional. Com base em tal atribuição, pode, e deve, realizar o controle dos atos ante os ditames constitucionais.

$\mathrm{O}$ TJ/RS entende, atualmente, que não cabe aos Tribunais de Contas realizar controle de constitucionalidade, mesmo na forma incidental. Afirmam que essa possibilidade é privativa

\footnotetext{
2 “Ao longo dos últimos anos, o mundo testemunhou uma transição surpreendentemente rápida para o que pode ser chamado de juristocracia". Tradução livre do original: "over the past few years the world has witness an astonishingly rapid transition to what may be called juristocracy". (HIRSCHL, 2004. p. 1).

Revista de Direito Brasileira | Florianólopis, SC | v. 25 | n. 10 | p. 56-71 | Jan./Abr. 2020
} 
do Poder Judiciário, e que a Súmula no 347 do STF não se mostra mais aplicável, considerado os dispositivos da Constituição de 1988.

Tal visão, todavia, é equivocada. Defender a impossibilidade de controle incidental pelo Tribunal de Contas é apequenar as importantes funções que o órgão desenvolve. Ainda, não encontra respaldo na Súmula $n^{\circ} 347$ e muito menos em julgados do STF, que permite o controle incidental por órgão de controle, como o CNJ.

As decisões que traduzem tal pensamento são por deveras equivocadas, e traduzem o juriscentrismo que impera na interpretação do Direito no mundo atual; não somente na interpretação do Direito, mas na relação entre os Poderes, o que ocasiona um desbalanceamento na harmônica relação entre os Poderes que a Constituição de 1988 instituiu.

\section{REFERÊNCIAS}

BARBOSA, Rui. Obras completas. v. XVIII, tomo III. Rio de Janeiro: Ministério da Educação e Saúde, 1946. Disponível em:

http://docvirt.com/docreader.net/docreader.aspx?bib=ObrasCompletasRuiBarbosa. Acesso em: 18 jul. 2019.

BINENBOJM, Gustavo. A nova jurisdição constitucional: legitimidade democrática e instrumentos de realização. 4. ed. rev., ampl. e atual. Rio de Janeiro: Renovar, 2014.

BITENCOURT, Caroline Müller; RECK, Janriê Rodrigues. A possibilidade de controle de constitucionalidade por parte do Tribunal de Contas: um estudo da Súmula n. 347 do STF e a posição do Tribunal de Justiça do Rio Grande do Sul. In: LEAL, Rogério Gesta;

BITENCOURT, Caroline Müller (org.). Temas polêmicos da jurisdição do Tribunal de Justiça do Rio Grande do Sul: matéria de corrupção e improbidade administrativa - estudo de casos vol. II. Porto Alegre: Tribunal de Justiça do Estado do Rio Grande do Sul, 2016. Disponível em:

https://www.tjrs.jus.br/export/poder_judiciario/tribunal_de_justica/centro_de_estudos/ebooks/ Temas_Polemicos_da_Jurisdicao_do_TJRS_Vol_II.pdf. Acesso em: 10 jul. 2019.

BONAVIDES, Paulo. Curso de direito constitucional. 15. ed. São Paulo: Malheiros, 2004.

BRASIL. Constituição da República Federativa do Brasil de 1988. Brasília, DF: Presidência da República, [2016]. Disponível em: http://www.planalto.gov.br/ccivil_03/Constituicao/Constituiçao.htm. Acesso em: 2 out. 2018.

BRASIL. Decreto $\mathbf{n}^{\circ}$ 966-A, de 7 de novembro de 1890. Crêa um Tribunal de Contas para o exame, revisão e julgamento dos actos concernentes á receita e despeza da Republica.

Brasília, DF: Presidência da República, [1890]. Disponível em: https://www.planalto.gov.br/ccivil_03/decreto/1851-1899/d00966-a.html. Acesso em: 15 jul. 2019.

BRASIL. Supremo Tribunal Federal (Tribunal Pleno). Petição n ${ }^{\circ}$ 4656/PB. [...] 3. Insere-se entre as competências constitucionalmente atribuídas ao Conselho Nacional de Justiça a possibilidade de afastar, por inconstitucionalidade, a aplicação de lei aproveitada como base de ato administrativo objeto de controle [...]. Requerente: Sindicato dos Servidores do Poder Judiciário do Estado da Paraíba - SINJEP. Requerente: Conselho Nacional de Justiça. Relator(a): Min. Cármen Lúcia, julgado em 19 de dezembro de 2016. Public. em 4 de dezembro de 2017. Disponível em:

http://portal.stf.jus.br/processos/detalhe.asp?incidente=3749362. Acesso em: 19 jul. 2019. 
BRASIL. Supremo Tribunal Federal. (Tribunal Pleno). Recurso de Mandado de Segurança 8372/CE. Não ofende a direito líquido e certo o ato do Tribunal de Contas que nega registro a aposentadoria fundada em lei revogada. Relator: Min. Pedro Chaves, 11 de dezembro de 1961. Public. em 26 de abril de 1962. Disponível em:

http://redir.stf.jus.br/paginadorpub/paginador.jsp?docTP=AC\&docID=108082. Acesso em: 19 jul. 2019.

BRASIL. Supremo Tribunal Federal. Súmula n 347. O Tribunal de Contas, no exercício de suas atribuições, pode apreciar a constitucionalidade das leis e dos atos do poder público. Brasília, DF: Supremo Tribunal Federal, [1963]. Disponível em: http://www.stf.jus.br/portal/jurisprudencia/listarJurisprudencia.asp?s1=347.NUME.\%20NAO \%20S.FLSV.\&base=baseSumulas. Acesso em: 15 jul. 2019.

CHADID, Ronaldo. A função social do Tribunal de Contas no Brasil. Belo Horizonte: Fórum. 2019. 262p.

DIMOULIS, Dimitri; LUNARDI, Soraya. Curso de processo constitucional: controle de constitucionalidade e remédios constitucionais. 4. ed. rev., atual. e ampl. São Paulo: Atlas, 2016.

GANT, Scott E. Judicial Supremacy and Nonjudicial Interpretation of the Constitution.

Hastings Constitutional Law Quarterly, vol. 24, no. 2, Winter 1997, p. 359-440. Base de dados HeinOnline. Disponível em: 〈http://heinonline.org/HOL/Welcome〉. Acesso em: 17 maio. 2020.

GOMES, Ana Cláudia Nascimento. O poder de rejeição de leis inconstitucionais pela autoridade administrativa no direito português e no direito brasileiro. Porto Alegre: Sergio Antonio Fabris Editor, 2002.

GUASTINI, Ricardo. La "constitucionalizacióin" del ordenamento jurídico: el caso italiano. In: CARBONELL, Miguel (Org.). Neoconstitucionalismo(s). 4. ed. Madrid: Editorial Trotta, 2009. p.49-69.

HIRSCHL, Ran. Towards juristocracy: The origins and consequences of the new constitutionalism. Cambridge: Harvard University Press, 2004.

HOBBES, Thomas. Do cidadão. Tradução, apresentação e notas Renato Janine Ribeiro. 3. ed. São Paulo: Martins Fontes, 2002.

LEITE, Glauco Salomão. Juristocracia e Constitucionalismo Democrático: Do ativismo judicial ao diálogo Constitucional. 1. ed. - Rio de Janeiro: Lumen Juris, 2017.

MEESE III, Edwin. The law of the Constitution. Tulane Law Review, v. 61, 1986-1987, p, 979-990.

MENDES, Gilmar Ferreira. Curso de direito constitucional. 10. ed. rev. e atual. São Paulo: Saraiva, 2015.

Gilmar Ferreira. O Poder Executivo e o Poder Legislativo no controle de constitucionalidade. Revista de Informação Legislativa. Brasília, ano 34, n. 134, p. 11-40, abr./jun. 1997.

MILESKI, Helio Saul. O controle da gestão pública. 2. ed. rev. atual. e aum. Belo Horizonte: Fórum, 2011. 
MIRANDA, Jorge. Manual de Direito Constitucional. Vol. III, tomo VI. Coimbra: Coimbra Editora, 2014.

MOURÃO, Licurgo; SHERMAM, Ariane; SERRA, Rita Chió. Tribunal de Contas democrático. Belo Horizonte: Fórum, 2018.

O SR. EX-MINISTRO DA FAZENDA. Jornal do Commercio, Rio de Janeiro, ano 71, n. 119, 30 de abril de 1893. Gazetilha, p. 2. Disponível em: http://memoria.bn.br/DocReader/364568_08/10876. Acesso em: 18 jul. 2019.

RIO GRANDE DO SUL. Tribunal de Justiça (Segundo Grupo de Câmaras Cíveis). Mandado de Segurança, $\mathbf{n}^{\mathbf{0}}$ 70079305702. [...] A declaração de inconstitucionalidade, ainda que de forma incidental, não é tarefa reservada à Corte de Contas, observado o sistema de controle de constitucionalidade instituído pela Constituição Federal em vigor [...]. Impetrante: Estado do Rio Grande do Sul. Autoridade coatora: Conselheiro Presidente da Segunda Câmara do TCE. Relator: Des. Eduardo Uhlein, 12 de abril de 2019. Public. 17 de abril de 2019. Disponível em:

https://www1.tjrs.jus.br/site_php/consulta/download/exibe_documento_att.php?numero_proc esso $=70079305702 \&$ ano $=2019 \&$ codigo $=548106$. Acesso em: 15 jul. 2019.

RIO GRANDE DO SUL. Tribunal de Justiça (Décimo Primeiro Grupo Cível). Mandado de Segurança, $\mathbf{n}^{\mathbf{0}}$ 70077675031. [...] Pode (e deve) o TCE fiscalizar o cumprimento da lei, o que é diverso de afastar a aplicação de dispositivo legal, que cumpriu o correspondente processo legislativo [...]. Impetrante: Estado do Rio Grande do Sul. Autoridade coatora: Conselheiro Relator do TCE. Relator: Des. Luiz Felipe Silveira Difini, 14 de dezembro de 2018. Public. 22 de janeiro de 2019. Disponível em:

https://www1.tjrs.jus.br/site_php/consulta/download/exibe_documento_att.php?numero_proc esso $=70077675031 \&$ ano $=2018 \&$ codigo $=2310340$. Acesso em: 15 jul. 2019.

RODRÍGUEZ-ARANA MUÑOZ, Jaime. Derecho administrativo y derechos sociales fundamentales. Sevilla: Global Law Press, 2015.

WILLEMAN, Marianna Montebello. Accountability democrática e o desenho institucional dos Tribunais de Contas no Brasil. Belo Horizonte: Fórum, 2017. 